\title{
Suitability of foramen magnum measurements in sex determination and their clinical significance
}

\author{
A. Metin Tellioglu1 , Y. Durum², M. Gok², S. Karakas ${ }^{1}$, A.G. Polat ${ }^{1}$, C.Z. Karaman² \\ ${ }^{1}$ Department of Anatomy, Faculty of Medicine, Adnan Menderes University, Aydin, Turkey \\ ${ }^{2}$ Department of Radiology, Faculty of Medicine, Adnan Menderes University, Aydin, Turkey
}

[Received: 10 April 2017; Accepted: 2 July 2017]

Background: The foramen magnum provides a transition between fossa cranii posterior and canalis vertebralis. Medulla oblongata, arteria vertebralis and nervus accessorius spinal part pass through the foramen magnum. In this study, we aimed to make the morphometric measurements of the foramen magnum on computed tomography (CT) and to determine the feasibility of sex determination based on these measurements. Besides sex determination, from a clinical aspect, it is important to know the measurements of the foramen magnum in the normal population in terms of diseases characterised by displacement of the posterior fossa structures through foramen magnum to upper cervical spinal canal such as Chiari malformations and syringomyelia.

Materials and methods: All the data for our study was obtained retrospectively from 100 patients (50 males, 50 females) who had a CT scan of the head and neck region in Adnan Menderes University Hospital, Department of Radiology. To examine the foramen magnum in each and every occipital bone, we measured the foramen magnum's anteroposterior diameter, transverse diameter, the area of the foramen magnum and its circumference.

Results: We found that men have a higher average value than women in our study. According to Student's t-test results; in all measured parameters, there is significant difference between the genders $(p<0.05)$. When multivariate discriminant function test is performed for all four measurements, the discrimination rate is $64 \%$ for all women, $70 \%$ for all men and $67 \%$ for both genders.

Conclusions: As a result of our study, the metric data we obtained will be useful in cases where the skeletons' sex could not be determined by any other methods. We believe that, our study may be useful for other studies in determining of sex from foramen magnum. Our measurements could give some information of the normal ranges of the foramen magnum in normal population, so that this can contribute to the diagnosis process of some diseases by imaging. (Folia Morphol 2018; 77, 1: 99-104)

Key words: foramen magnum, sex determination, multidetector computed tomography images 


\section{INTRODUCTION}

Gender is one of the main biological properties that can be determined from skeletal remains. By looking at the pelvis and cranium from a full skeleton the accuracy of sex determination is almost $100 \%$ [16]. When the skeleton is partial; different bones of the skeleton play an important role in determination of sex from the skeleton. Particularly, the pelvis and cranium, long bones such as the femur, tibia, ulna, humerus and radius, sternum, calcaneus, talus and lots of other bones were used by many researchers for this purpose $[2,5,14,15,19,20,22]$. Sex determination can be very challenging in the cases of comminuted ancient skeleton remnants, mass disasters like war zones and plane crashes, comminuted skeleton remnants in terrorist attacks or explosions [17]. Therefore more resistant small skeleton remnants in such cases can be important in sex determination. The foramen magnum, which is in occipital bone, is one of these resistant skeleton parts. The cranial base can provide better results than any other parts of the skull due to its relative thickness, protectivity due to its anatomical position and resistance to physical damage. Therefore, this region has an important role in the process of sex determination [24].

In recent years, forensic databases can be obtained from skeleton remnants with the help of computed tomography (CT) in forensic medicine [25]. Magnetic resonance imaging (MRI) and particularly multi-detector CT are widely used for post-mortem examinations [21].

In most of the previous studies about morphometric measurements, dry bones were used [6]. In our study the foramen magnum from three-dimensional (3D)-CT images of the Turkish population were measured with the aim of determining whether these measurements were useful for sex determination.

There are many diseases that can affect the measurements of the foramen magnum, with Chiari malformation being the primary. Chiari malformation is a congenital anomaly of the craniovertebral junction and hindbrain, which is associated with variable displacement of the posterior fossa structures through the foramen magnum to the upper cervical spinal canal. Syringomyelia is a chronic process in which longitudinal cystic spaces develop in the spinal cord and, therefore, spinal cord compression results in neurological findings. Syringomyelia and Chiari malformations are very closely related and there are many theories about the development of syringomyelia associated with Chiari malformations [4, 11]. Some studies have proved that foramen measurements show deviations from normal ranges in such diseases $[3,26]$.

\section{MATERIALS AND METHODS}

Before commencing the study, approval was obtained from the Adnan Menderes University Noninterventional Clinical Trials Ethics Committee. All the data for our study was obtained retrospectively from 100 patients ( 50 males, 50 females, adults between the ages of 19-88) who had a CT scan of the head and neck region in Adnan Menderes University Hospital, Department of Radiology, between January 2014 and January 2015. All demographic information was obtained from their recorded clinical files. Patients, who had head and neck examinations with non-specific symptoms (headache, dizziness etc.) were included in the study, however, patients with fractures and advanced degeneration in the head and neck region were excluded.

Routine CT protocol for the head and neck region was used for this study, so there was no need for a new CT protocol. An 80-row detector 160 slice CT System (Aquilion Prime, Toshiba Medical Systems, Nasu, Japan) and high-resolution parameters $(80 \times 0.5 \mathrm{~mm}$ detector collimation, $1 \mathrm{~mm}$ slice section thickness, 120 $\mathrm{kV}$ ) were used to obtain transverse, sagittal and coronal images. The slice in which the foramen magnum was widest was obtained from the images parallel to the foramen magnum. In this slice, first the widest anterior-posterior (AP) diameter and transverse diameter was measured. This was followed by measuring the area of the foramen magnum by manually drawing automatic area calculator programme (Figs. 1, 2) The measurements were reobtained after 2 weeks by the same person and the average of these two measurements were noted.

\section{Statistical analysis}

All data obtained were analysed using SPSS 18.0 software. Compliance of the normal distribution of data were analysed by Kolmogorov-Smirnov test. Because all variables were normally distributed, descriptive statistics were shown as mean \pm standard deviation (SD). In comparison of sex groups, Student's $t$ test was used. Using discriminant analysis, we then calculated as a percentage, the rate at which gender could be correctly identified. 


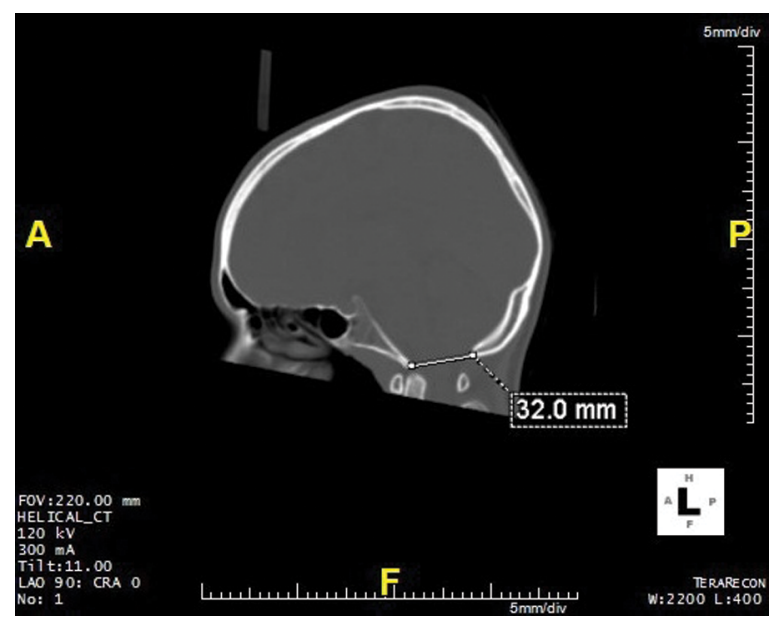

Figure 1. Foramen magnum anterior-posterior (AP) diameter on sagittal plane.

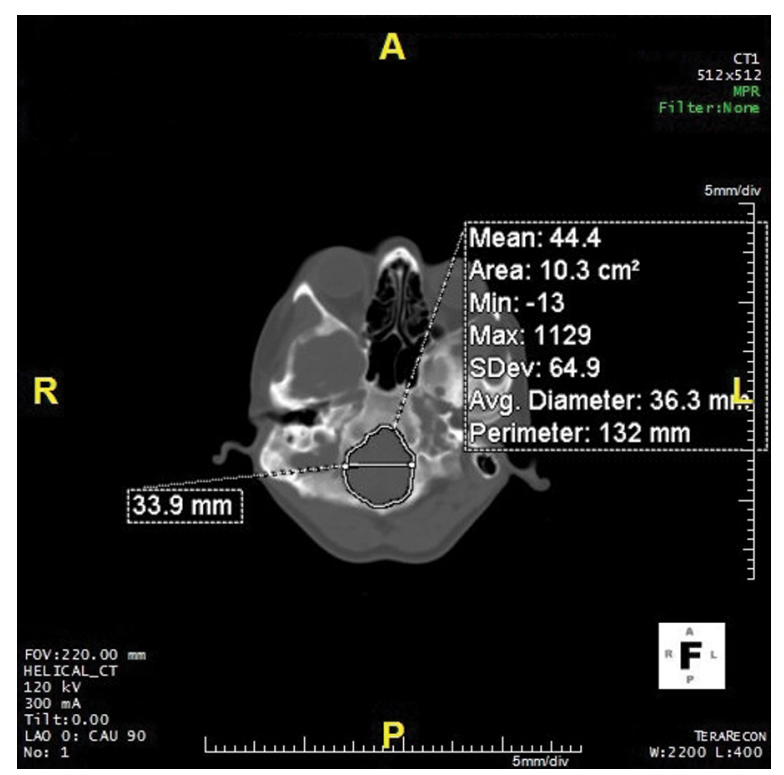

Figure 2. Foramen magnum transverse diameter, area and circumference on axial plane.

\section{RESULTS}

All measurement findings, obtained from 3D-CT images of 100 (50 women, 50 men), are shown in Tables 1-4. After reviewing all 100 images, mean AP diameter was $33.86 \pm 2.58 \mathrm{~mm}$, transverse diameter was $29.48 \pm 2.68 \mathrm{~mm}$, circumference was $116.45 \pm$ $\pm 10.21 \mathrm{~mm}$ and area was $7.72 \pm 1.09 \mathrm{~cm}^{2}$ (Table 1). In men mean AP diameter was $34.73 \pm 2.21 \mathrm{~mm}$, transverse diameter was $30.47 \pm 2.25 \mathrm{~mm}$, circumference was $119.82 \pm 10.23 \mathrm{~mm}$ and area was $8.17 \pm$ $\pm 1.09 \mathrm{~cm}^{2}$. In women mean AP diameter was $32.99 \pm$ $\pm 2.65 \mathrm{~mm}$, transverse diameter was $28.4 \pm 2.72 \mathrm{~mm}$, circumference was $113.08 \pm 9.09 \mathrm{~mm}$ and area was $7.27 \pm 0.9 \mathrm{~cm}^{2}$. According to Student's t-test results, in all measured parameter there was significant difference between the genders ( $p<0.05)$. In all of the measured variables, men had higher average values than women (Table 2).

The discriminant function analyses of all measurements related to the foramen magnum are shown in Tables 3 and 4. In Table 3, the arithmetic means of the values are shown. Every measurement from the foramen magnum was considered as univariate for gender discrimination and according to univariate discriminant function test, the most reliable variable was AP diameter with $69 \%$ gender discrimination value. In women the most reliable discriminant variable was area with $72 \%$. In men the most reliable discriminant variable was transverse diameter with $68 \%$ (Table 3). When multivariate discriminant function test was performed for all four measurements, the discrimination rate was $64 \%$ for all women, $70 \%$ for all men and $67 \%$ for both genders (Table 4 ).

\section{DISCUSSION}

There are some extraordinary situations where sex determination is required, such as in the case of explosions, terrorist attacks, mass disasters like earthquakes and plane crashes. Such situations are extraordinary because it is not possible to utilise the whole skeleton, so sex determination needs to be done with smaller skeletal remains. Sex determination with small pieces will save time and reduce the costs for forensic anthropologists before starting detailed research (DNA analysis, etc.) [10]. Due to its anatomical position and endurance, the foramen magnum can be used for sex determination. The foramen magnum has accordingly attracted the attention of researchers for this purpose.

As we reviewed the literature, most of the studies about the foramen magnum were done mostly on dry bones [9]. Today all these measurements can be obtained from radiological images. The measurements by Gabert et al. [8] on skeletons from $18^{\text {th }}$ and $19^{\text {th }}$ century from the foramen magnum with univariate functions sex determination accuracy is $68.8 \%$ and with multivariate functions this number is $70.3 \%$. According to the study by Raghavendra Babu et al. [23], on dry skulls' of Indian population, receiver operating characteristic analysis shows that the transverse diam- 
Table 1. Descriptive statistics of the variables

\begin{tabular}{lccccc}
\hline Variables & N & Minimum & Maximum & Mean & SD \\
\hline Anterior posterior diameter & 100 & 27.30 & 39.54 & 33.86 & 2.58 \\
Transverse diameter & 100 & 21.90 & 35.76 & 29.48 & 2.68 \\
Circumference & 100 & 86.60 & 162.00 & 116.45 & 10.21 \\
Area & 100 & 5.39 & 11.00 & 7.72 & 1.09 \\
\hline
\end{tabular}

SD — standard deviation

Table 2. Sex differences for variables

\begin{tabular}{lcccc}
\hline Variables & Female $(\mathbf{n}=\mathbf{5 0})$ & Male $(\mathbf{n}=\mathbf{5 0})$ & \multicolumn{2}{c}{ Sex differences } \\
\cline { 4 - 5 } & Mean \pm SD & Mean \pm SD & T-value & P-value \\
\hline Anterior posterior diameter & $32.99 \pm 2.65$ & $34.73 \pm 2.21$ & 3.541 & $<0.001$ \\
Transverse diameter & $28.4 \pm 2.72$ & $30.47 \pm 2.25$ & 3.973 & $<0.001$ \\
Circumference & $113.08 \pm 9.09$ & $119.82 \pm 10.23$ & 3.384 & $<0.001$ \\
Area & $7.27 \pm 0.9$ & $8.17 \pm 1.09$ & 4.497 & $<0.001$ \\
\hline
\end{tabular}

SD - standard deviation

Table 3. Accuracies and demarcation points resulted from univariate discriminate function analysis

\begin{tabular}{lcccc}
\hline Variables & \multicolumn{3}{c}{ Original accuracy (\%) } & Demarcation points \\
\cline { 2 - 4 } & Male & Female & All groups & \\
\hline Anterior posterior diameter & 68 & 70 & 69 & $\mathrm{~F}<33.86<\mathrm{M}$ \\
Transverse diameter & 68 & 64 & 66 & $\mathrm{~F}<29.48<\mathrm{M}$ \\
Circumference & 58 & 66 & 62 & $\mathrm{~F}<116.45<\mathrm{M}$ \\
Area & 64 & 72 & 68 & $\mathrm{~F}<7.72<\mathrm{M}$ \\
\hline
\end{tabular}

F-females; $M$ - males

Table 4. Multivariate discriminant function analysis

\begin{tabular}{|c|c|c|c|c|c|c|c|}
\hline \multirow[t]{2}{*}{ Variables } & \multirow{2}{*}{$\begin{array}{l}\text { Unstandardised } \\
\text { coefficient }\end{array}$} & \multirow[t]{2}{*}{ Wilks' lambda } & \multicolumn{2}{|c|}{ Centroids } & \multicolumn{3}{|c|}{ Original accuracy (\%) } \\
\hline & & & Male & Female & Male & Female & All groups \\
\hline \multicolumn{8}{|l|}{ Constant $=-14.002$} \\
\hline All four variables & & $0.829^{*}$ & 0.493 & -0.493 & 70 & 64 & 67 \\
\hline Anterior posterior diameter & 0.164 & $0.801^{*}$ & & & 68 & 70 & 69 \\
\hline Transverse diameter & 0.149 & $0.887^{*}$ & & & 68 & 64 & 66 \\
\hline Circumference & 0.010 & $0.867^{*}$ & & & 58 & 66 & 62 \\
\hline Area & 0.379 & $0.890^{*}$ & & & 64 & 72 & 68 \\
\hline
\end{tabular}

Discriminant function equation $=-14.002+(0.164 \times \mathrm{FMAP})+(0.149 \times \mathrm{FMT})+(0.010 \times \mathrm{FMC})+(0.379 \times \mathrm{FMA})$. A discriminant function score greater than 0.000 indicates male and less than 0.000 indicates female. All sectioning points are zero. ${ }^{*}$ Significant $(p<0.01)$.

eter's estimation rate is $65.4 \%$, the anterior posterior diameter's estimation rate is $86.5 \%$ and with different formulation of area the estimation rate is as high as $81.6 \%$ and $82.2 \%$ [23]. On the contrary, according to Kamanth et al. [13] the estimation rate is $70.3 \%$ with area measurement. The study of Uthman et al. [27], in which the foramen magnum measurements done through CT images, revealed that the foramen 
magnum circumference and area measurements were best discriminant parameters with $67 \%$ and $69.3 \%$ accuracy rates. In addition to that, using multivariate analysis they found that the gender was detected correctly in $90.7 \%$ of men and $73.3 \%$ of women [27]. In our study, we tested the availability of the sex determination of the measurements made from the foramen magnum of the Turkish population. Two statistical models are prominent in the evaluation of metric data obtained for sex determination. One of these models is based on regression equations, and the other is based on discriminant functional analysis. In this study we used discriminant functional analysis. According to the univariate discriminant function test, the most reliable variable in our results is AP diameter with $69 \%$ discrimination rate. In this respect, our results were close to the results of Raghavendra Babu et al. [23]. When a multivariate discriminant function test was performed, this variable was able to detect $64 \%$ of women and $70 \%$ of men. According to the study of Uthman et al. [27], with multivariate discriminant function, the detection rate is $90.7 \%$ for men and $73.3 \%$ for women, which is higher than our results [23]. We believe that the difference is based on variability of genetic and environmental factors between the populations tested.

Besides the foramen magnum, there are many other regions within the cranium which have been used for sex determination. Dong et al. [7] found that with the measurements obtained from CT images of the mandible, the sex determination rate was $84.2 \%$. Jain et al. [12] showed that from the measurements of mastoid triangle and opisthion-bimastoid triangle, asterion-mastoidale length has an $80 \%$ and mastoid breadth has a $75 \%$ determination rate. In the study of Akhlaghi et al. [1], where they reviewed the frontal sinus parameters from paranasal sinus CT images, they found that the left frontal sinus maximum height has a $61.3 \%$ determination rate.

The foramen magnum measurements will help to enlighten the pathophysiology of Chiari syndrome, basilar invagination, as well as sex determination. According to a study by Aydin et al. [3], in 60 patients with Chiari type I malformation and 30 patients in control group, the foramen magnum anteroposterior and midsagittal diameters were significantly increased in patient group compared to the control group, in MRI of posterior cranial fossa [3]. In a case report of Ulutabanca et al. [26] with Chiari type I malformation, they emphasized the effectiveness of the foramen magnum and posterior cranial fossa measurements in differential diagnosis of tonsillar herniation and the estimation of surgical results of Chiari type I malformation [26]. In their study of 17 Chiari type I malformation patients and 30 control patients, Noudel et al. [18] emphasized that the foramen magnum measurements had a greater mean in the patient group than in the control group MRI. Our results demonstrate the mean measurements of the foramen magnum with $\mathrm{CT}$ images in normal population.

\section{CONCLUSIONS}

As in other regions of the skeleton and cranium, our study showed that the foramen magnum can be used for sex determination. The data from this study would contribute to the literature on sex determination of the Turkish population. This study also provides guidance on how CT can be used for anthropological studies. Our measurements may contribute to the radiological diagnosis of some diseases by giving and idea about the measurements of the foramen magnum of the normal population.

\section{REFERENCES}

1. Akhlaghi M, Bakhtavar K, Moarefdoost J, et al. Frontal sinus parameters in computed tomography and sex determination. Leg Med (Tokyo). 2016; 19: 22-27, doi: 10.1016/j. legalmed.2016.01.008, indexed in Pubmed: 26980249.

2. Albanese J. A method for estimating sex using the clavicle, humerus, radius, and ulna. J Forensic Sci. 2013; 58(6): 1413-1419, doi: 10.1111/1556-4029.12188, indexed in Pubmed: 23865634.

3. Aydin S, Hanimoglu H, Tanriverdi T, et al. Chiari type I malformations in adults: a morphometric analysis of the posterior cranial fossa. Surg Neurol. 2005; 64(3): 237-41; discussion 241, doi: 10.1016/j.surneu.2005.02.021, indexed in Pubmed: 16099255.

4. Cesmebasi A, Loukas M, Hogan E, et al. The Chiari malformations: a review with emphasis on anatomical traits. Clin Anat. 2015; 28(2): 184-194, doi: 10.1002/ca.22442, indexed in Pubmed: 25065525.

5. Chandrakanth HV, Kanchan T, Krishan K. Osteometric analysis for sexing of modern sternum - an autopsy study from South India. Leg Med (Tokyo). 2014; 16(6): 350-356, doi: 10.1016/j.legalmed.2014.07.007, indexed in Pubmed: 25127732.

6. Cirpan S, Yonguc GN, Mas NG, et al. Morphological and Morphometric Analysis of Foramen Magnum: An Anatomical Aspect. J Craniofac Surg. 2016; 27(6): 1576-1578, doi: $10.1097 /$ SCS.0000000000002822, indexed in Pubmed: 27607122.

7. Dong H, Deng M, Wang W, et al. Sexual dimorphism of the mandible in a contemporary Chinese Han population. Forensic Sci Int. 2015; 255: 9-15, doi: 10.1016/j. forsciint.2015.06.010, indexed in Pubmed: 26146162. 
8. Gapert R, Black S, Last J. Sex determination from the foramen magnum: discriminant function analysis in an eighteenth and nineteenth century British sample. Int J Legal Med. 2009; 123(1): 25-33, doi: 10.1007/s00414008-0256-0, indexed in Pubmed: 18553095.

9. Gruber $\mathrm{P}$, Henneberg $\mathrm{M}$, Böni $\mathrm{T}$, et al. Variability of human foramen magnum size. Anat Rec (Hoboken). 2009; 292(11): 1713-1719, doi: 10.1002/ar.21005, indexed in Pubmed: 19777568.

10. Hartman D, Drummer O, Eckhoff $C$, et al. The contribution of DNA to the disaster victim identification (DVI) effort. Forensic Sci Int. 2011; 205(1-3): 52-58, doi: 10.1016/j. forsciint.2010.09.024, indexed in Pubmed: 21106312.

11. Isik N. Chiary Malformation and Syringomyelia. Türk Nöroşirürji Dergisi. 2013; 23(2): 185-194.

12. Jain $D$, Jasuja OP, Nath $S$. Sex determination of human crania using Mastoid triangle and OpisthionBimastoid triangle. J Forensic Leg Med. 2013; 20(4): 255-259, doi: 10.1016/j.jflm.2012.09.020, indexed in Pubmed: 23622470.

13. Kamath VG, Asif M, Shetty R, et al. Binary logistic regression analysis of foramen magnum dimensions for sex determination. Anat Res Int. 2015; 2015: 459428, doi: 10.1155/2015/459428, indexed in Pubmed: 26346917.

14. Karakas HM, Harma A, Alicioglu B. The subpubic angle in sex determination: anthropometric measurements and analyses on Anatolian Caucasians using multidetector computed tomography datasets. J Forensic Leg Med. 2013; 20(8): 1004-1009, doi: 10.1016/j.jflm.2013.08.013, indexed in Pubmed: 24237808.

15. Kranioti E, Apostol M. Sexual dimorphism of the tibia in contemporary Greeks, Italians, and Spanish: forensic implications. Int J Legal Med. 2015; 29(2): 357-363, doi: 10.1007/s00414-014-1045-6.

16. Kranioti EF, Işcan MY, Michalodimitrakis M. Craniometric analysis of the modern Cretan population. Forensic Sci Int. 2008; 180(2-3): 110.e1-110.e5, doi: 10.1016/j.forsciint.2008.06.018, indexed in Pubmed: 18718728.

17. Lain R, Taylor J, Croker S, et al. Comparative dental anatomy in Disaster Victim Identification: Lessons from the 2009 Victorian Bushfires. Forensic Sci Int. 2011; 205(1-3): 36-39, doi: 10.1016/j.forsciint.2010.06.008, indexed in Pubmed: 20605076.

18. Noudel R, Jovenin N, Eap C, et al. Incidence of basioccipital hypoplasia in Chiari malformation type I: comparative morphometric study of the posterior cranial fossa. Clinical article. J Neurosurg. 2009; 111(5): 1046-1052, doi: 10.3171/2009.2.JNS08284, indexed in Pubmed: 19463049.

19. Peckmann TR, Orr K, Meek $S$, et al. Sex determination from the talus in a contemporary Greek population using discriminant function analysis. J Forensic Leg Med. 2015; 33: 14-19, doi: 10.1016/j.jflm.2015.03.011, indexed in Pubmed: 26048490.

20. Peckmann TR, Orr K, Meek S, et al. Sex determination from the calcaneus in a 20th century Greek population using discriminant function analysis. Sci Justice. 2015; 55(6): 377-382, doi: 10.1016/j.scijus.2015.04.009, indexed in Pubmed: 26654070.

21. Petju M, Suteerayongprasert A, Thongpud R, et al. Importance of dental records for victim identification following the Indian Ocean tsunami disaster in Thailand. Public Health. 2007; 121(4): 251-257, doi: 10.1016/j. puhe.2006.12.003, indexed in Pubmed: 17276465.

22. Purkait R. Triangle identified at the proximal end of femur: a new sex determinant. Forensic Sci Int. 2005; 147(2-3): 135-139, doi: 10.1016/j.forsciint.2004.08.005, indexed in Pubmed: 15567617.

23. Raghavendra Babu YP, Kanchan T, Attiku Y, et al. Sex estimation from foramen magnum dimensions in an Indian population. J Forensic Leg Med. 2012; 19(3): 162-167, doi: 10.1016/j.jflm.2011.12.019, indexed in Pubmed: 22391003.

24. Tambawala SS, Karjodkar FR, Sansare K, et al. Sexual dimorphism of foramen magnum using cone beam computed tomography. J Forensic Leg Med. 2016; 44: 29-34, doi: 10.1016/j.jflm.2016.08.005, indexed in Pubmed: 27591340.

25. Torimitsu S, Makino $Y$, Saitoh $H$, et al. Morphometric analysis of sex differences in contemporary Japanese pelves using multidetector computed tomography. Forensic Sci Int. 2015; 257: 530.e1-530.e7, doi: 10.1016/j. forsciint.2015.10.018, indexed in Pubmed: 26553274.

26. Ulutabanca H, Acer N, Küçük $A$, et al. Chiari type I malformation with high foramen magnum anomaly. Folia Morphol. 2015; 74(3): 402-406, doi: 10.5603/FM.2015.0059, indexed in Pubmed: 26339825.

27. Uthman AT, Al-Rawi NH, Al-Timimi JF. Evaluation of foramen magnum in gender determination using helical CT scanning. Dentomaxillofac Radiol. 2012; 41(3): 197-202, doi: 10.1259/ dmfr/21276789, indexed in Pubmed: 22116135. 